\title{
Feminilidade/verdade e seus disfarces
}

\author{
Jerzuí Mendes Tôrres Tomaz
}

Pode-se pensar a literatura como uma forma de o homem interrogarse sobre si mesmo. $\mathrm{O}$ discurso literário, lugar onde todas as transgressões são permitidas, busca ler o humano na sua vivência quotidiana, bem como no seu destino histórico.

É fato que a linguagem não diz exatamente nem verdadeiramente o que parece dizer, linguagem que possui duplo valor de verdade e alienação. A psicanálise, como a "arte de decifrar uma verdade", leva-nos a pensar as possíveis relações existentes entre o inconsciente e as produções literárias. Freud, através de audaciosas análises de clássicos da literatura, evidencia que todo e qualquer texto apresenta uma parte de inconsciência. Sedutores criptogramas/hieróglifos que podem e devem ser decifrados, remetendonos à constatação de que no plano simbólico, nada é gratuito, tudo é significante.

É lícito afirmar que não é mais possível inocência diante da obra de arte, inexistindo ingenuidade na interpretação de um texto ficcional. Somos incapazes de nos desvencilhar dos fantasmas que permeiam a leitura. A produção literária é, pois, o grande palco onde a multiplicidade de egos de quem sobre ela se debruça, podem ser postos em cena. Nisso reside a sedução textual, que ressoa em cada indivíduo de acordo com suas ficções, fantasias e mitos, remetendo ao processo transferencial da experiência analítica.

A teoria psicanalítica sustenta que nós, seres de linguagem (falasseres), ou seres atravessados pela linguagem, somos inevitavelmente desejantes. Desejo que nos impulsiona e constitui, pondo em movimento Eros e Thanatos. Desejo que remete a uma falta, "falta de ser" e nos põe em busca de um objeto irremediavelmente perdido e sempre alucinado. Nesta perspectiva, a obra literária pode apresentar-se como "don juanesca, porque

Psicanalista e mestranda em Letras - UFAL 
ela se funda sempre numa promessa: promessa de realizaçào de um desejo" (BRANDÃO, 1993, p. 1 56).

Joel Birman afirma que o motor do processo crítico é precisamente este desejo, o que viabiliza romper com a inércia dos significantes, gerando inusitadas produções de sentido (BIRMAN, 1996, p. 61 ).

No leitor que se defronta com traços de escritura, ocorre algo do estatuto de um impacto (impacto no ser), denunciando a dimensão irruptiva da leitura/interpretação. Ler é defrontar-se com fragmentos textuais que desconcertam os sistemas de referência do indivíduo, produzindo rupturas, descontinuidades, revelando a positividade de um desejo. Neste processo, ocorre toda uma oscilação entre pólos de atividade e passividade. O lugar do sujeito no campo da escritura assume, deste modo, o duplo papel de interpretante e interpretado. Para o crítico literário é fundamental a razão e o entendimento, mas este não pode prescindir do corpo erógeno, local onde a insistência do mais-saber se inscreve.

Mas existirá afinal a verdade/interpretação última sobre a produção dos escritores? Derrida nos adverte que "um texto só é um texto se ele oculta ao primeiro olhar, ao primeiro encontro, a lei de sua composição e a regra de seu jogo. Um texto permanece, aliás, sempre imperceptível” (DERRIDA, 1972, p. 17).

A ciência de Freud, por sua vez, evidencia que o não-sentido é a origem de todo sentido. É no jogo com as palavras, essas "partículas minúsculas de pequeno sentido", que o inusitado pode advir na cadeia discursiva. Desde que se renuncie à certeza e ao gozo do significado. Embora, a "condição da leitura é evidentemente que ela imponha limites a si mesma” (LACAN, 1985, p. 89).

Em determinado momento do seu ensino, Jacques Lacan faz uma equiparação entre a mulher e a verdade (LACAN, 1985, p. 62), ambas representadas como inalcançáveis, escorregadias, inatingíveis.

O romance crônica da casa assassinada*, do escritor mineiro Lúcio Cardoso, tematiza de forma magistral esta provável impossibilidade do saber sobre a mulher e a verdade. E um desdobramento destas questões que pretendo aqui desenvolver.

A Crônica é uma reunião de textos que tem como tema central uma figura feminina. Toda a trama gira em torno de um não-saber sobre Nina.

A partir de agora, os trechos citados deste romance serão referenciados apenas pelo número da página. 
Um não-saber que provoca inúmeras teorias, suposições, ficções, enriquecendo o imaginário de uma pequena cidade interiorana - Vila Velha.

É numa dimensão de algo que não se sabe como abordar, de algo perigoso e ameaçador, que a personagem central vem situar-se no universo de ficção de Lúcio Cardoso. O enredo relata a saga de uma família mineira, outrora rica e poderosa, no confronto com uma bela mulher vinda "de fora", uma autêntica personificação do unbeimlich; palavra alemã que se relaciona com o que é assustador, com o que provoca medo e horror, tendo por equivalente em português o vocábulo estranbo. "O estranho é aquela categoria do assustador que remete ao que é conhecido, de velho, e há muito familiar" (cf. FREUD 1 1, p. 277). A trajetória de Nina junto aos Meneses estende-se desde a sua chegada esplendorosa, até sua morte em tom sacrificial.

O romance em questão compõe-se de uma série de manuscritos: diários, narrativas, cartas, confissões, depoimentos, movidos pela curiosidade e o desejo de se saber quem é realmente esta enigmática criatura... Capaz de associar beleza e feminilidade, bem como espalhar tensão, estranheza, perigo e suspeita. Seria uma dama de sangue azul ou uma cantora de cabaré?

Todas as personagens falam sobre Nina, muito se teoriza sobre ela, mas nunca se diz tudo acerca desse enigma que parece ser o da própria feminilidade. O que há de comum em todos estes discursos é a associação que se faz entre Nina - a morte - a destruição.

Vejamos o depoimento de Betty, a governanta dos Meneses, primeira pessoa a vê-la:

[...] jamais. jamais poderei esquecer a impressão que me causou. Não foi um simples movimento de admiração, pois já havia me deparado com muitas mulheres belas em minha vida. Mas nenhuma como esta conseguiu misturar no meu sentimento de pasmo essa leve ponta de angústia, essa ligeira falta de ar que, mais do que a certeza de me achar ante uma mulber extraordinariamente bela, forjou-me também a reconhecer que se tratava de uma presença - um ser egoista e definido que parecia irradiar a própria luq e o calor da paisagem (p. 52 - grifo do autor).

Para Valdo, marido de Nina e responsável pela vinda da mulher que se transformou no objeto do desejo dos habitantes da Chácara e até mesmo 
de Vila Velha, sua esposa personificava perigo e sortilégio. Quem sabe por esta "estranha" ser capaz de questionar os atributos imaginários que se constituíam no sustentáculo da decadente família Meneses. Nas palavias do próprio personagem, pode-se ouvir:

De que modo brutal não amei eu esta criatura, no tempo em que a amava, para reconbecer e aceitar assim os signos da minha própria morte e as possibilidades da minha destruição? $\mathrm{Ou}$ - e aqui não ouso mais do que sugerir, sem ter coragem para ir mais longe - não terá sido precisamente isto, a imagem da minha morte, o que me arrebatou de modo tão decisivo? ( $p$. 151).

Em alguns momentos, dá-se um silêncio forçado, instaura-se uma aura de mistério em torno de Nina. André, seu provável filho e depois ardoroso amante, é proibido pelo pai (Valdo) de fazer qualquer referência àquela que se ausentou do convívio familiar por longos anos. Mas não é difícil constatar que "o ser humano não para de querer falar daquilo que não pode dizer (a mulher, a morte, o pai, etc.)" (ANDRÉ, 1987, p. 10). No entanto, a presença ausência materna, a força do interdito, transparece no seguinte trecho:

Eu sabia que não poderia indagar a seu respeito. que ninguém me diria coisa alguma, e ainda assim nentum assunto me interessou mais do que aquele. [...] Nunia vira um retrato seu, nem pessoa alguma me falara a seu respeito. E que importava afinal como tivesse sido? - a uinica coisa importante é que um mistério pairava sobre sua vida [...]. Pois apesar desse silêncio e de seu nome constar como uma coisa morta em nossa casa, tudo o que tocava, os lugares por onde transitava, o jardim e a varanda falavam a seu respeito (p. 212).

Mas, não será justamente da dimensão imaginativa (lugar de reflexos e de miragens) que nós, pobres humanos, somos alimentados? Lacan nos assegura que há sempre alguma coisa na mulher que escapa ao discurso. E Nina parece resistir a toda e qualquer nomeação. Seria um anjo, ou um 
demônio? Uma vez que a mulher se confunde com a verdade, o teórico francês citado afirma que só podemos semi-dizê-la (LACAN, 1987, p. 141).

Admitindo-se a premissa que um texto se edifica a partir da falta, do silêncio e do vazio, entende-se mais facilmente o discurso fragmentário das várias personagens-narradoras que integram o romance em debate. Há toda uma polifonia de vozes que ecoam de diversos lugares e de diferentes perspectivas. O que se observa é uma construção textual labiríntica, um autêntico jogo de espelhos, onde as imagens se repetem e se contradizem. A cadeia discursiva (formada por diários, confissões, cartas, narrativas) é sempre descontínua, com lacunas e silêncios que marcam a passagem de uma inscriçào a outra. A história que o autor pretende narrar é plenamente descentrada e as inúmeras falas são, necessariamente, incessantes e inesgotáveis. Uma vez que esse significante - Nina - remete à própria dinâmica metafórica, incapaz de se deixar aprisionar, sempre deslizando para um mais-além.

Diante da impossibilidade de se saber a verdade sobre a narrativa, e Lúcio Cardoso encena, diabolicamente, essa impossibilidade, Nina funciona como "um coringa ou um objeto fálico" (BRANDÃO, 1993, p. 265).

No envolvimento com Demétrio, o todo-poderoso chefe do clã Meneses, essa personagem representa inicialmente uma "anormalidade", uma "excrescência", num ambiente onde o novo não tinha lugar. Mas a mulher inquieta, irritadiça, amante do luxo, elegante e sedutora, é capaz de desencadear uma avassaladora paixão no homem antes circunspecto e senhor de si. No entanto, ao rejeitar o próprio cunhado, a esposa de Valdo transforma-se no mal que deveria ser extirpado a qualquer preço. Instala-se o imbricamento do amor e ódio ("amódio") ou amor e morte na relação entre os dois. Num jogo de enganos, de palavras fingidas, dá-se um pacto entre Demétrio e o farmacêutico da cidade, envolvendo a compra de uma arma de fogo. O revólver, como representante da pulsão de morte que habita Demétrio, destina-se a destruir aquela que ameaçava toda a tradição e os valores da Chácara.

Acontece que, o trajeto do revólver também vai ser marcado por deslocamentos, desvios, equívocos e mudanças de alvo. Se é Nina que deve ser eliminada, quem se fere é Valdo e quem morre é Alberto, o jardineiro da família e objeto do desejo de Tímóteo (irmão mais novo de Demétrio) e também de Nina. 
Em determinados trechos do romance, percebe-se a narrativa como uma possível armadilha para o leitor, confundindo-se os lugares da mulher e da morte. Lúcio Cardoso parece querer mostrar os muitos disfarces da verdade/feminilidade. O texto cardosiano "provoca a dúvida, inquieta, mente, simula, engana, teatraliza a verdade, joga com o leitor" (RODRIGUES, 1996, p. 71). É o perigoso phármakon', com seu poder de criação e de morte, onde se entrecruzam palavras, dor e gozo...

Sabe-se que o destino da feminilidade na doutrina freudiana é problemático. Freud sempre enfatizou seu caráter irracional, misterioso, até mesmo perigoso. À mulher foi dado 0 estatuto de enigma e obscuridade. Enigma que assume um duplo papel dependendo do sexo: faz falar os homens e calar as mulheres (ANDRÉ, 1987, p. 204). Acredito que daí advenha a inevitável associação entre mulher-mistério-mistificação-mentira. $\mathrm{O}$ estatuto do ser feminino constitui-se, pois, num ponto de interrogação e demarca um furo, uma lacuna inominável que resiste ao próprio discurso.

Diante dessas questões, o que se pode esperar do confronto entre dois "seres falantes que se alinham sob a bandeira das mulheres?" (LACAN, 1985, p. 98). Para Ana Meneses, a insípida esposa de Demétrio, Nina não passa de uma "cadela das ruas, prostituta, ser anormal e monstruosa" (p. 205). É importante assinalar que Ana chega a incorporar tão fortemente os valores do seu núcleo familiar, que pode confundir-se com uma "peça" ou um "detalhe" dos móveis do antigo casarão. Por muitos é descrita como um ser destituído de graça, em que tudo parecia evocar a opacidade. O seu embate com Nina assume o efeito de uma revelação, uma miragem num espelho terrífico e ameaçador. Segundo sua declaração:

Othei-me depois ao espelho e assustou-me a minha palider. meus vestidos escuros, minha falta de graça. Repito, repito indefinidamente, era a primeira vez que aquilo me acontecia e eu fitava minha própria imagem como se estivesse diante de uma estrangeira (p. 103).

\footnotetext{
' Derrida equipara a escritura com o pharmákon, que pode servir tanto de remédio como ocupar o lugar de veneno. "Pharmákon quer dizer em grego droga curativa, veneno, tintura, mas sempre, para o melhor ou para o pior, em um sentido mágico" (cf. DERRIDA, p.84).
} 
Pode-se pensar que a principal função de Nina na Crônica é representar a mulher, exibindo todos os atributos imaginários relativos ao sexo feminino. Suas belas roupas, seus cabelos bem cuidados, o "tênue perfume de violetas" são signos que vêm compor o "corpo feminino". Sabe-se que é através desses artifícios/adornos que ela será alvo dos olhares tanto masculinos, quanto femininos. Não nos esquecendo que o "olhar" é, por excelência, um dos objetos do desejo... O teórico Serge André afirma que "assim, a falta de ter o falo, a mulher cuida particularmente de sua imagem corporal, de tal sorte que esta chega a adquirir o valor de falo: à falta de ter um signo identificatório do pênis, ela tem um corpo feminino" (ANDRÉ, 1987, p. 115 - grifo do autor).

Lacan, ao refletir sobre essas questões, constata que não há significante do sexo feminino. Faltaria um apoio para uma identificação especificamente feminina, uma vez que a metáfora paterna é insuficiente para atribuir a um sujeito seu lugar de mulher. Daí a imagem corpórea do propalado "sexo frágil" aparecer sempre como algo tênue e vacilante.

Mas é preciso dar forma e materialidade a esta entidade diáfana que teima em escapar. Assim, o traje das mulheres, com todo o seu caráter de sedução, busca demarcar uma borda, um limite, que garanta sustentação à evanescência inerente à feminilidade. Pois, "quando uma mulher se enfeita, suas roupas, suas jóias, sua voz, mascaram uma nudez que não é a do corpo, mas sim a do fallus" (SOUZA apud BRANDÃO, 1985, p. 135 - grifo do autor).

É na busca de uma possível "essência" do feminino que tanto deseja, que Ana se deixa aprisionar pelo fascínio de Nina. A Outra Mulher assume a encarnação da própria feminilidade. A final, quem mais poderá saber o que é um "corpo de mulher"? Quem deterá o poder de decifrar o enigma do que significa "ser uma mulher"?

Presa ao reflexo especular que constitui/desconstitui, Ana revela sentimentos de rancor e intolerância. Apesar disso, sente necessidade da força, beleza e onipotência de Nina para continuar vivendo. Inveja "aquele ímpeto bruto, aquela cegueira na conquista de seus apetites” (p. 187). E se deixa corroer pelo ciúme. Explicado psicanaliticamente pelo fato da "opositora" possuir um quê que a torna irresistível, capaz de captar magicamente o desejo masculino. A tentativa de aprender este "traço" que não existe, leva as mulheres a rastreá-lo umas nas outras, incessantemente. O mistério da feminilidade é, e não poderia ser de outra forma, alimentada 
pelo desejo masculino, pois o que uma mulher ama não é propriamente o pretendido parceiro, mas o desejo que ele tem por outra. Aqui cabe o ensinamento de Lacan, tributário de Hegel, quando designa o desejo humano como desejo de desejo.

Para o enfadonho mundo dos Meneses, Nina é perigosa por se constituir como um ser desejante. $\mathrm{O}$ que quer uma mulher? Essa questão relançada e que nunca obtém resposta, remete à impossibilidade do saber: sobre Nina, sobre o amor, sobre a verdade, sobre a mulher.

A teoria psicanalítica revela que o sujeito do discurso é sempre clivado e dividido. A Crônica, um romance que encena a incompletude da verdade e a impossibilidade da representação do feminino, tem como característica uma espécie de interdito que permeia os textos que a compõem. As declarações são apresentadas de forma indireta, narrativas embutidas em outras narrativas, onde é impossivel localizar o eu narrador. Os personagens, por sua vez, vivem da vida alheia, dos sentimentos alheios, num incessante jogo de esconde esconde, onde há apresentação de fatos que contradizem verdades anteriormente enunciadas.

Não será forçado uma equiparação entre o estilo descritivo de Lúcio Cardoso e a representação feminina inconsciente que "se constitui por objetos parciais, por inscrições que se fazem uma a uma, como suplementos de um não-todo" (BRANDÃO. 1993, p. 273). Diante da instigante inquietude do feminino, o leitor, incansável criador de novos sentidos, é irremediavelmente aprisionado ao feitiço da escritura, vivenciando a linguagem como o lugar do encobrimento e da trapaça.

A irrupção de Nina na província mineira suscita discursos os mais diversos. "Diziam-na perigosa, fascinante e cheia de autoridade" (p. 43). Valdo vislumbrava no seu rosto uma "tristeza indevassável" (p. 62) e o médico da família via na sua beleza um "signo de fatalidade" (p. 48).

E quais as impressões de Timóteo, o filho caçula e execrável ovelha negra? Para o "rebento espúrio dos Meneses", Nina era dotada de uma força ativa e transcendente. Disposta a desafiar leis expressas e adentrar em limites interditados. É importante assinalar que algo da ordem da transgressão já outrora marcara o orgulhoso núcleo familiar, através de uma excêntrica ancestral - Maria Sinhá. Uma mulher "atirada ao limiar de si mesma", que percorria os pastos desenfreadamente, ajudando os vaqueiros em suas atividades, domando bezerros e cavalos bravos. Maria Sinhá que ousara despudoradamente romper com a ordem estabelecida, invertendo papéis 
masculinos/femininos, abrindo espaço para a desordem e indiferenciação sexual que terá em Timóteo seu ponto culminante.

Para seus irmãos, o filho mais moço de D. Malvina era um ser doente e maldoso, condenado por Demétrio ao confinamento. Alimentando um ódio implacável em relação a todos que o cercavam, incapaz de aceitar sua perversão sexual (homossexualismo) sem desprezar-se, Timóteo reconhece em Nina a pessoa que poderá efetivar seus planos de vingança. O próprio "anjo exterminador" que iria ajudá-lo a destruir todos os Meneses. Do envolvimento entre sujeitos tão incomuns, produz-se algo da ordem do retorno do recaliado ${ }^{2}$. Pois só o cadáver de Nina, por ocasião do seu velório, tem o poder de descerrar as portas da prisão do homem condenado ao silêncio. A aparição de tão grotesca criatura (trajando vestido de franjas e lantejoulas e exibindo no corpo jóias adquiridas por herança) causa espanto, indignação, dor, repulsa, piedade. É o momento em que vêm à luz os significantes familiares submetidos ao recalque.

Timóteo, o herdeiro involuntário dos signos maternos, através de uma imagem corporal alegórica, também remete ao impossivel de se definir as fugidias insígnias da feminilidade.

Sabe-se que as lacunas na narrativa textual são uma das condições do simbólico, uma vez que há sempre um resto que não pode ser simbolizado, algo que escapa à nomeaçào. Constata-se inclusive que o pensamento (logus) é insuficiente na expressão da realidade psíquica e do desejo que nos atravessa. Na produção dos escritores, esses geniais criadores de metáforas, não existe palavra inocente e as várias versões da verdade também podem ser ditas no silêncio (interdito).

No imaginário literário masculino, a mulher é muitas vezes representada como um perigo que deve ser eliminado. Diante do vazio da feminilidade, o ser mulher apresenta-se ora de forma castrada, ora fálica demais, revelando

\footnotetext{
${ }^{2}$ Terminologia freudiana que remete ao caráter indestrutivel dos conteúdos inconscientes. A noção de recalcamento é fundamental no arcabouço teórico da psicanálise, no qual surge como correlativo do próprio conceito de inconsciente. O retorno do recalcado é, deste modo, uma operação dinâmica, posta em causa pela força do desejo inconsciente, que procura trazer à tona os elementos psíquicos que foram afastados da consciência pela operação de recalcamento. Segundo Freud, o processo em questão se manifesta através de sintomas, sonhos, atos falhos, chistes, etc. (cf. LAPLANCHE, J. \& PONTALIS, J.B., p. 601 - 60s).
} 
algo da ordem do não senso e da morte. Definida através da privação, da perda, da falta.

Esse é o lugar ocupado por Nina na trama narrada por Lúcio Cardoso, onde se confunde com o discurso da fragmentação e do não-todo. Nina como unbeimlich, atravessada, cortada, assassinada pela palavra do outro. Nina com uma fala sobre si mesma que conduz à desordem e à desrazão.

Já foi anteriormente enfatizado que todos os relatos da Crônica da casa assassinada versam sobre o desconhecimento sobre Nina e a impossibilidade de se alcançar a verdade. Quando o romance chega ao seu desenlace, a escritura cala sobre o que o leitor quer saber (desejo de certeza). Os depoimentos sobre a personagem central não coincidem. Fragmentários e contraditórios, roubam-nas a ilusão de unicidade. Tenta-se uma reconstituição, uma resignificação de fatos anteriormente vivenciados, mas o que se obtém é uma "realidade" por demais plural, pois, como afirma Ruth Silviano Brandão:

Referindo-se a Nina, cada personagem apenas expressa algo de si mesma e de seus afetos que nela se centram. Nina acaba por se revelar o espelho desejado ou renegado, onde elas se contemplam, tentando-se reconhecer ou negando-se ai mesmo onde se vêem (1993. p. 268).

O saber da Psicanálise sobre a feminilidade denota claramente uma hiância. O feminino como o lugar do silêncio, do mutismo e da impossibilidade do registro significante, fundamenta as equiparações entre a mulher e as figuras representativas da morte. E Lacan, ao enunciar o paradoxo "A mulher não existe", apenas retoma a tese freudiana segundo a qual, a feminilidade não é um ser, mas um se tornar (ANDRÉ, 1987, p. 27). A grande questão a se colocar é que fora da anatomia, não sabemos o que encobrem os termos masculino/feminino, ou só temos nebulosas aproximações, uma vez que a diferença anatômica não se inscreve como tal ao nível do psiquismo. Inexistindo, deste modo, uma "essência" especificamente feminina.

Assim, menino e menina, jogam unicamente com o significante da falta, uma vez que o falo ninguém o é, ou o tem, definitivamente.

Freud, ao postular o determinismo inconsciente, produziu uma revolução sem precedentes na concepção do homem. Enriquecendo a 
contribuição freudiana, Jacques Lacan vem acrescentar que este determinismo é o da própria linguagem, uma vez que "não há realidade prédiscursiva. Cada realidade se funda e se define por um discurso" (LACAN, 1987 , p. 145). Discurso que funciona como um liame entre aqueles que falam.

Diante desse viés teórico, é inevitável se pensar em "feminilidade" e "masculinidade", como funções de linguagem, como possibilidades lógicas, indicativas da posição do sujeito na cultura.

A feminilidade, múltipla em significados, rebelde às soluções definitivas, é uma construção linguageira. Se as mulheres são um conjunto aberto e devem ser contadas uma por uma, por outro lado, são elas que abrem aos homens a possibilidade da criação. $O$ vazio inerente ao feminino vem funcionar como lugar de produção de inesgotáveis metáforas.

E em relação à verdade, o que se pode dizer? E fato que Psicanálise e Literatura não são pragmáticas no sentido de garantirem um controle ou mestria de seus efeitos simbólicos. A verdade - como um saber advindo da linguagem - também é feita de teorias e ficções. O ser humano, irremediavelmente alienado do seu desejo inconsciente, constata que "toda a verdade, é o que não se pode dizer. É o que só se diz com a condição de não levá-la até o fim, de só se fazer semi-dizê-la (LACAN, 1987, p. 124). Lúcio Cardoso corrobora esta assertiva ao declarar, pela voz de Timóteo, que "a verdade é uma ciência solitária" (p. 37), que tem como suporte a palavra, palavra que dissimula, vacila, engana.

O homem como criador de convenções lingüísticas, formadas por sinais arbitrários e impregnadas de uma contextualidade histórica, desmascara a ilusão de uma relação direta entre palavras e coisas. As "verdades" são, inescapavelmente, metáforas.

Aí reside o fascínio da escritura/textualidade que deve sempre ser encarada como risco, jogo, simulação.

Na tentativa de interpretação de uma obra literária é vetada a busca de qualquer sentido primitivo ou originário. Este trabalho, por demais subjetivo, deve centrar-se nos vestígios do que se mostra e do que se esconde... Só assim será viável romper com signos instituídos e encarar o fato de que não há certezas, nem caminhos pré-estabelecidos. E aí haverá abertura para as trilhas luminosas do ato criador...

Joel Birman acredita que as incontáveis veredas da feminilidade, ajudam-nos a vencer o desamparo da existência. Com a renúncia da crença em enunciados universais, poderá o sujeito humano inventar para si novos 
destinos, abrindo espaço para modalidades outras de erotismo e sublimação.

$\mathrm{Na}$ relação leitor/texto, a subjetividade do interpretante/interpretado é posta em questão, ao tempo em que algo a respeito do seu ser e do seu desejo é revelado. E aquele que uma vez se debruça sobre uma obra ficcional, jamais será o mesmo.

Retomando-se a questão inicial do que define a mulher e onde se esconde a verdade, pode-se pensar esta equação (mulher/verdade) como essa coisa por demais diáfana, cortina de seda que tremula, dependendo do jogo de luz do desejo de cada ser que a esse respeito se interroga.

E uma vez que Freud, ao ser inquirido sobre um mais-saber sobre a feminilidade, remete-nos aos poetas, deixemos a última palavra com Rainer Maria Rilke:

Figura de mulher, em seu sono

encerrada, dir-se-ia que ela degusta

algum ruido, a nenhum outro semelhante

que a preenche toda.

De seu corpo sonoro que dorme

ela tira o gozo

de ser ainda um murmúrio

sob o olhar do silêncio

(RILKE apud ANDRÉ. 1987. p. 89). 


\section{Referências bibliográficas}

1. ANDRÉ, Serge. O que quer uma mulher? Rio de Janeiro: Jorge Zahar,1987.

2. BIRMAN, Joel. Por uma estilistica da existência. São Paulo: Editora 34, 1996.

3. BRANCO, Lúcia Castello \& BRANDÃO, Ruth Silviano. A mulher escrita. Rio de Janeiro: Casa-Maria Editorial: LTC - Livros Técnicos e Científicos Editora, 1989.

4. BRANDÃO, Ruth Silviano. Mulher ao pé da letra. Belo Horizonte: Editora UFMG, 1993.

5. BRASIL, Hórus Vital. Dois ensaios entre psicanálise e literatura. Rio de Janeiro: Imago, 1992.

6. CARDOSO, Lúcio. Crônica da Casa Assassinada. Rio de Janeiro: TECNOPRINT, [s.d.].

7. CHEMAMA, Roland (Org.). Dicionário de psicanálise. Porto Alegre: Artes Médicas, 1995.

8. DERRIDA, Jacques. A farmácia de Platão. São Paulo: Iluminuras, 1991.

9. FREUD, Sigmund. "Feminilidade". In: Obras Completas de Sigmund Freud. Rio de Janeiro: Imago, Edição Standard Brasileira, 1976, v. 22.

10. "Sexualidade Feminina". In: Obras Completas de Sigmund Freud. Rio de Janeiro: Imago, Edição Standard Brasileira, 1976, v. 21. 11. "O estranho". In: Obras Completas de Sigmund Freud. Rio de Janeiro: Imago, Edição Standard Brasileira, 1976, v.11.

12. ."Escritores Criativos e Devaneio". In: Obras Completas de Sigmund Freud. Rio de Janeiro: Imago, Edição Standard Brasileira, 1976 , v. 9. 
13. KON, Noemi Monitz. Freud e seu duplo: reflexões entre psicanálise e arte. São Paulo: EDUSP, 1996.

14. LACAN, Jacques. Seminário 20: mais, ainda. Rio de Janeiro: Jorge Zahar, 1985.

15. LAPLANCHE, J. \& PONTALIS, J.B. Vocabulário da psicanálise. São Paulo: Martins Fontes, 1985.

16. RODRIGUES, Victor Hugo Guimarães. "As armadilhas da desconstrução: as estratégias do texto nas aproximações entre Derrida e o Zaratustra de Nietzsche". Cadernos Niet ssche: Revista do Departamento de Filosofia da USP - Vol. 1, p. 69 - 82, São Paulo, 1996.

17. STERN, J.P. As idéias de Nietzsche. São Paulo: Cultrix, 1978. 